\title{
DYNAMIC OPTIMIZATION MODEL FOR GARMENT DUAL- CHANNEL SUPPLY CHAIN NETWORK: A SIMULATION STUDY
}

\author{
Zhang, L. \\ College of Business Administration, Zhejiang University of Finance \& Economics, Hangzhou, China \\ E-Mail: leinuo_zhang@163.com
}

\begin{abstract}
This paper aims to explore the optimization tactics of a dual-channel production and distribution network based on pre-sale mode to address the current situation of overstocked inventories in the apparel industry and considering the effect of changing production-distribution modes on apparel sales which results from the difference of order decoupling point. The research indicates that in the highly homogeneous apparel market, the pre-sale mode in which the products are made-to-order can utilize the highly efficient feedback of online pre-sales to provide guidance for traditional distribution channel by making accurate demand forecasts in a certain environment. This could help to resolve the problem of overstocked inventories by providing relative reference for the apparel industry in its subsequent operations. The mode of the production-distribution network after optimization is able to make reference to the real operations of pre-sale mode in the apparel industry.

(Received, processed and accepted by the Chinese Representative Office.)
\end{abstract}

Key Words: Dual-Channel, Pre-Sale Mode, Supply Chain Network, Dynamic Optimization

\section{INTRODUCTION}

Apparel is a unique kind of perishable goods, especially high fashion apparel products, which are characterized by seasonal consumption, short life cycles, low demand predictability and prominent demand differentiation, all of which contribute to the significant variability and time-sensitive nature of the apparel supply chain. The structure of apparel supply chain is quite complex and the disparity between the long chain and fast demand variability leads to production management often falling behind the rapidly changing market. This leads to a great deal of inventory flowing into the downstream sales channel. Hence the over inventory in apparel supply chain has been the development bottleneck of the whole industry. On the other hand, with the rapid development of e-commerce, online shopping has gradually penetrated the consumption market. The number of all online shopping transactions reached 2.8 trillion in China during 2014, among which 615.3 billion were apparel transactions, so online shopping for apparel has become a purchasing method in the domestic apparel consumption market.

To effectively solve the problem of overstocking, apparel manufacturing enterprises have extended traditional marketing channels to some new modes such as $\mathrm{C} 2 \mathrm{C}, \mathrm{C} 2 \mathrm{~B}, \mathrm{O} 2 \mathrm{O}$, virtual fitting room etc. As a new type of e-commerce, online pre-sales can rapidly centralize independent consumption demand throughout the country and effectively integrate consumers' preference information through the e-commerce platform, providing a valuable reference for the traditional distribution channels. Meanwhile, the online pre-sale mode can effectively bring scale production and individualized demand together, which would provide new opportunities for apparel inventory control and industry development.

The remainder of this paper is organized as follows. Section 2 briefly reviews related literature. Section 3 describes the problem considered in this paper. Section 4 presents the mathematical formulation of the model. Section 5 presents an empirical case to demonstrate 
the feasibility and effectiveness of this model. Conclusions and recommendations are summarized in the final section.

\section{LITERATURE REVIEW}

\subsection{Research status on apparel supply chain}

The European Commission provided financial aid to a research plan named Textile Production and Supply Chain in 2004, with the goal of building a supply chain of haute couture which can adapt to demand variability. Subsequently, many scholars did research projects on the apparel supply chain from various points of view.

Lowson et al. [1] conducted research on the high cost of the apparel supply chain being is caused by the long average delay time, and with the concept of a quick response system he finally pointed out that the supply chain can shorten the delay time to respond consumer demand. Bergvall and Towers [2] put forward the concept of elasticity supply chain, pointing out that in such a supply chain system, not only can the retailers effectively and timely adjust the inventory according to market information, but also can maintain an efficient strategic partnership with manufacturers.

To reduce the sales loss cost, the backlogs of orders and the outdated inventory, Fisher et al. [3] built a two-stage random dynamic supply chain model. They determined the amount of initial order and replenishment of high fashion retail products with a short life cycle by utilizing an heuristic algorithm and chose the optimal ordering time. Considering the supply chain system under a dual-channel environment, Chiang and Monahan [4] proposed a twostage supply chain inventory model in which the inventory are kept in manufactures' warehouses and retailers' warehouses. The simulation indicated that the dual-channel strategy can improve the flexibility of the supply chain system while at the same time reducing the cost. Gao [5] started with the dynamics of apparel inventory, exploring strategies and methods to reduce inventory. He built a contract model and made analysis, improving retail efficiency of high fashion products by effective inventory control and management.

Brun and Castelli [6] discussed the effects of products, brands and channel characteristics on the fashion industry supply chain. They pointed out that these three elements have different hierarchical relations in affecting the difference the of supply chain. Li et al. [7] discussed the optimal pricing strategy under both centralized and decentralized decision making of the garment supply chain with repurchasing strategy and they obtained the solution with optimal balance. Zhou and $\mathrm{Xu}$ [8] pointed out that risk comes with uncertain demand making accurate predictions difficult in the apparel supply chain. They built a simulation model with system dynamics and solved the efficiency problem of supply chain operation in the VMI mode, and finally he verified the optimization performance of VMI by numerical simulation. Considering RFID and other techniques, Xu [9] built a storage-distribution optimization model to make available intelligent management for the inventory distribution of the apparel supply chain available.

\subsection{Research status on pre-sale strategy}

Pre-sale strategy has been considered an effective means and has received much attention from scholars globally, and related research mainly explores problems such as pre-sales and demand prediction. Weng and Parlar [10] firstly explored how enterprises advance sales by making discounts, and the model made an assumption that demand in the pre-sale stage is influenced by the discount quota, but it neglected the consumers' purchase risk in pre-sale stage. On this basis, Tang et al. [11] researched optimal pre-sale discount under random demand in the pre-sale stage, analysing the utility of using the actual amount of pre-sales to 
predict demand in sales season. Moe and Fader [12] researched the effects of a pre-sale deadline on the spreading of new products, and by empirical research they verified that the pre-sale information has played a helpful role in demand prediction of new products. Li et al. [13] researched the pre-sales strategy when both product demand and consumer evaluation are uncertain. The higher correlation between pre-sale demand and normal sale demand, the more obvious the pre-sale advantages. Through the pre-sale mode individual scattered demand as a sort of patch-work can be rapidly brought together in a short time. Boyaci and Ozer [14] researched the problems of market information obtained through pre-sale mode and determined the productivity according to the market information.

At present, there is little literature regarding research on production-distribution network of fashionable products under pre-sale strategy [15], and the existing research projects have neglected the stage features of fashionable products [16-18], not taking the products' characteristics and channel structures into consideration. So, the urgent tasks for apparel enterprises in the near future are to analyse the service content and operation modes of online channels and traditional channels based on pre-sale mode, to explore the effective integration between online channels and tradition channels to realize collaborative operations of a dualchannel supply chain, and to further improve the supply chain efficiency. On the basis of online pre-sale mode, this paper brings the stage sales characteristics of apparel products into the supply chain network structure, considering the preference constraint of products availability. The paper built a production-distribution network including manufacturers, distributors and retailers in a dual-channel environment and analysed the effect of pre-sale mode on inventory according to the optimization results. The results indicate that the information from online pre-sales can improve the accuracy of demand prediction of the traditional distribution channel, control the shortage cost and effectively resolve the problem of overstocking of apparel products.

\section{PROBLEMS DESCRIPTION AND ILLUSTRATION}

\subsection{Problems description}

Garment products can be divided into seasonal and basic classes, with the seasonal fashion class accounting for almost $80 \%$ of the whole market share. The seasonal fashion apparel is characterized by a short life cycle, quick updating and high demand instability etc. Before the sales season, the apparel enterprises would display their seasonal fashion products with new styles in the online shop for pre-sale, thus to centralize the consumer demand quickly while at the same time effectively integrating consumers preference information. The factory will adopt the MTO mode after receiving pre-sale orders and make distribution directly after production. With a rapid growth in demand, the enterprises adopt MTS mode in which the products will be sold through both online channels and traditional channels at the same time to shorten the response time. At the end of sales, the apparel enterprises with traditional distribution channels provide feedback about remaining inventory to online sellers, and the online distributors sell the remains. So the backlog of inventory in the traditional channel can be sold online through the online distributors and can then be collaboratively distributed by traditional distribution channels. The basic apparel has high demand stability. Enterprises can make accurate predictions according to the existing sales data, so for this kind of products, the MTS mode should be adopted to realize scale effect. The basic products are stocked and distributed through the traditional distribution channels, while at the same time being sold through online sale channels, but the sold-out basic products are distributed through the traditional distribution channel and the online sellers need to afford a certain amount of logistics cost to traditional distributors. The flow path of a supply chain network based on presale mode is as shown in Fig. 1. 


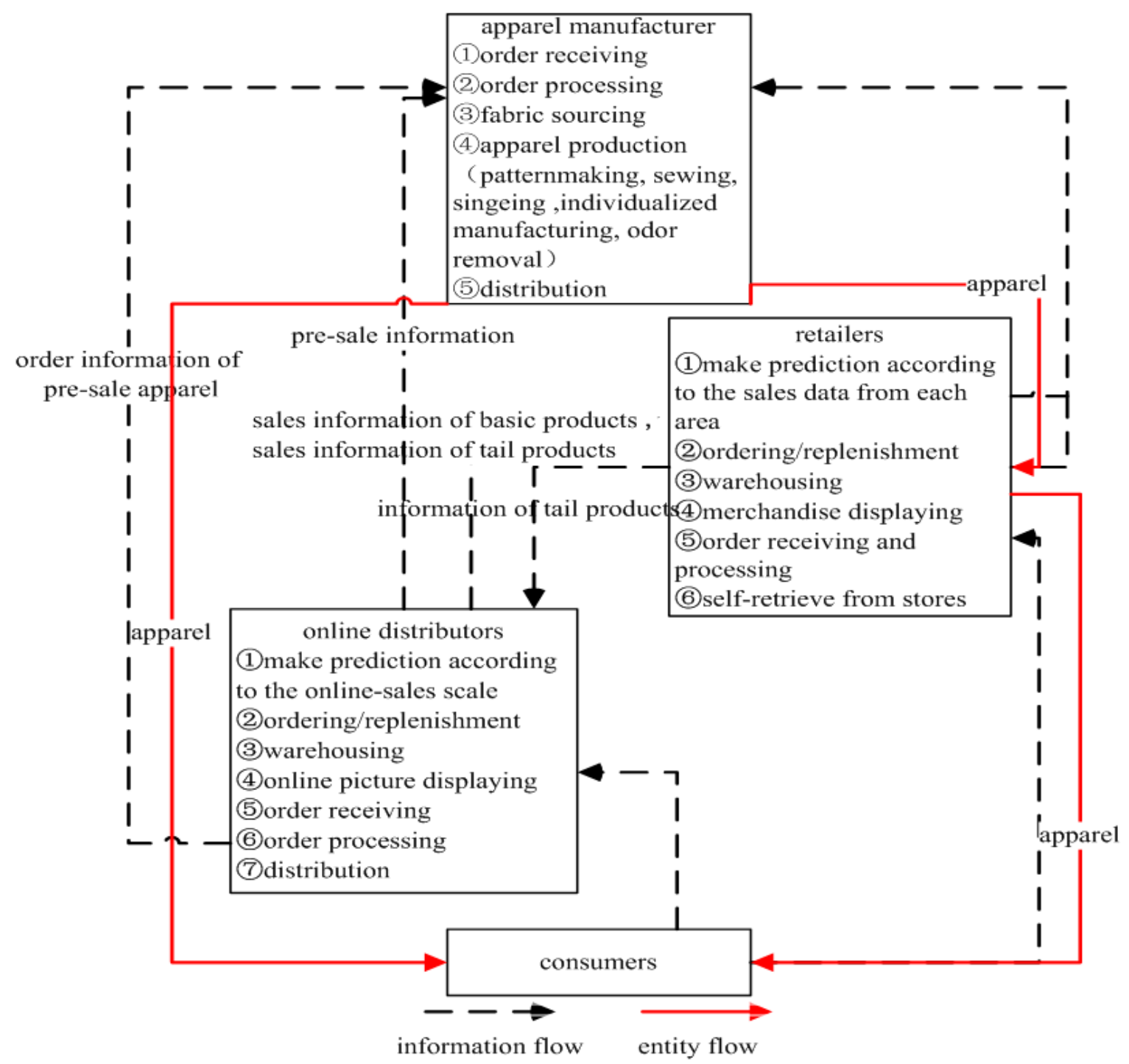

Figure 1: The flow path of apparel supply chain network based on pre-sale mode.

From the description above, it is clear that the apparel supply chain system based on presale mode is obviously distinguished from the traditional supply chain in the structure of the production-distribution network. To maximize profit, apparel enterprises must determine the production scale, distribution amount and inventory, etc. of different apparel in different situations. So, the production quantity and logistic amount in each path is set to continuous decision variables and a mixed-integer programming model is built to realize collaborative optimization of the supply chain network system.

\subsection{Model assumptions and parameters}

To simplify the model, the following assumptions are made:

(1) The lapsed customers in the online-sale channel will not purchase in traditional distribution channels.

(2) The market demand, prices of the two channels and available time are of linear correlation; the channels prices and cross price influence the demand; the available time increases as the demand decreases.

(3) The delivery delay of products sold through online channels will generate penalty costs.

(4) In the same channel, the prices in each market are the same for one kind of product. 
(5) The traditional distribution channel adopts $(t, S)$ replenishment strategy; namely when the inventory drops to a safe stock, an instant inventory supplement will be made.

The mathematical notation and formulation are as follows:

(1) Superscripts and subscripts:

$P$ : product sets, $P=\{1,2,3\}$ respectively represent new seasonal fashion products 1 and 2 and basic product $3, p \in P$;

$T$ : sale stage sets, $T=\{1,2,3\}$ respectively represent sale prophase, sale metaphase and sale anaphase, $t \in T$;

$F$ : factory sets, $f \in F$;

$W$ : channel sets, $W=\{1,2\}$ respectively represent online channel and traditional channel, $w \in W$;

$M$ : market sets, $m \in M$.

(2) Capacity parameters:

$p a_{f t}$ : the productivity constraint of factory $f$ in stage $t$;

$g_{\text {wpt }}$ : the safe stock amount of product $p$ in each stage and each channel.

(3) Demand parameters:

$D_{w p t}$ : the demand of product $p$ in channel $w$ in stage $t$;

$a_{p t}$ : the basic demand of product pin stage $t$;

$\theta$ : the market share of online distribution channel;

1- $\theta$ : the market share of traditional distribution channel;

$\alpha_{w m}$ : the market share of channel $w$ in market $m$;

$b$ : the price flexibility coefficient;

$c$ : the cross-price flexibility coefficient;

$p c_{w p t}$ : the price of product $p$ in channel $w$ in stage $t$;

$D o_{\text {wpt }}$ : the demand prediction of product $p$ in each channel $w$ and each stage according to the sales data of last season.

(4) Cost parameters:

$c p_{f p t}$ : the unit production cost of product $p$ in factory $f$ in stage $t$;

$c q_{\text {wpt }}$ : the unit shortage cost of product $p$ in channel $w$ in stage $t$;

$c f$ : the penalty coefficient caused by the delay of products;

$c s_{p t}$ : the unit storage cost of product $p$ in traditional channel in stage $t$;

$c w_{f p t}$ : the unit transportation cost from factory $f$ to traditional distribution channel;

$\mathrm{cm}_{m p t}$ : the unit transportation cost from traditional distribution channel to market $m$;

$c t_{f m p t}$ : the unit transportation cost from factory $f$ to market $m$.

(5) Time parameters:

$d s$ : the sensitivity coefficient;

$t p_{f p t}$ : the variable production time of product $p$ in factory $f$ in stage $t$;

$\operatorname{tg}_{f p t}$ : the fixed production time of product $p$ in factory $f$ in stage $t$;

$c g$ : the lead time of factory to purchase cloth from suppliers;

$t w_{p t}$ : the delivery time that factory promises to product $p$ in traditional distribution channel in stage $t$;

$t m_{t}$ : the delivery time that the online channel promises to customers;

$t s_{m p t}$ : the actual delay time of product $p$ to market;

$t a_{f p t}$ : the unit transportation time of product $p$ from traditional distribution channel to distributors in stage $t$;

$t b_{m 3 t}$ : the unit transportation time of basic product 3 from traditional distribution channel to market in stage $t$;

$t c_{f m p t}$ : the unit transportation time of product $p$ from each factory to market in stage $t$.

(6) Decision variables:

$x_{f p t}$ : the production amount of products $p$ in stage $t$; 
$\zeta_{\text {wpt }}$ : the shortage amount of products $p$ in channel $w$ in stage $t$;

$y_{f p t}$ : the output amount of products $p$ from factory $f$ to traditional distribution channel in stage $t$;

$z_{m p t}$ : the output amount of products $p$ from traditional distribution channel to market $m$ in stage $t$;

$z z_{m p t}$ : the sales amount of products $p$ in online distribution channel in stage $t$;

$s_{f m p t}$ : the freight amount of products $p$ from factory $f$ to market $m$ in stage $t$;

$w p_{p t}$ : the storage amount of products $p$ in traditional distribution channel in stage $t$.

\section{MODEL BUILDING AND SOLVING}

\subsection{Demand function establishment}

Because of the lower price, the online sales channel may occupy the market share of the traditional distribution channel, while the fast availability of the traditional distribution channel attracts the customers with time sensibility. According to the assumption (2), the demand is a linear function under the influence of both, its own and cross price effects, so the demands of two channels are respectively as follows:

$$
\begin{gathered}
D_{1 p t}=\theta \mathrm{a}_{p t}-b \cdot p c_{1 p t}+c \cdot p c_{2 p t}-d s \cdot t m_{t}, \quad \forall t \in T, \quad p \in P \\
D_{2 p t}=(1-\theta) \mathrm{a}_{p t}-b \cdot p c_{2 p t}+c \cdot p c_{1 p t}, \quad \forall t \in T, \quad p \in P
\end{gathered}
$$

\subsection{The model of apparel production-distribution network based on pre-sale mode}

$$
\begin{aligned}
\text { Max } & =\sum_{t \in T} \sum_{w \in W} \sum_{p \in P} p c_{w p t}\left(D_{w p t}-\xi_{w p t}\right)-\sum_{t \in T} \sum_{w \in W} \sum_{p \in P} c q_{w p t} \xi_{w p t} \\
& -\sum_{f \in F} \sum_{p \in P} \sum_{t \in T} c p_{f p t} x_{f p t}-\sum_{t \in T} \sum_{p \in P} c s_{p t} w p_{p t}-\sum_{t \in T} \sum_{f \in F} \sum_{p \in P} c w_{f p t} y_{f p t} \\
& -\left(\sum_{t \in T} \sum_{m \in M} \sum_{p \in P} c m_{m p t} z_{m p t}+\sum_{f \in F} \sum_{m \in M} \sum_{p \in P} \sum_{t \in T} c t_{f m p t} s_{f m p t}\right) \\
& -c f \sum_{m \in M} \sum_{t \in T} \sum_{p \in P} t s_{m p t}
\end{aligned}
$$

In Eq. (3), the first item is sales revenue in channel, the second item is the shortage caused by insufficient output, the third item is production cost, the forth item is storage cost caused by product surplus, the fifth item is transportation cost from factory to warehouse, the sixth item is transportation cost from factory to market, the seventh item is penalty cost caused by delay in delivery to market.

1) Time constraint

Online distributors display the styles and colours of the products for pre-sale to the consumers, and the pre-sale products will be produced according to the orders. Without stock of raw materials, the factory purchases cloth from suppliers according to the pre-sale orders, but a long lead time will make the seasonal products has worse availability. Eq. (4) represents the time constraint of seasonal products from production to market.

$$
\sum_{f \in F} t p_{f p t} s_{f m p t}+\sum_{f \in F} t c_{f m p t} s_{f m p t}+c g-t s_{m p t} \leq t m_{p t}, \forall m \in M, \quad t \in T, p=1,2
$$

The online distribution channel displays the detail information of product 3 to the consumers. As the online distribution channel has no inventory, product 3 is distributed 
through the traditional distribution channel. Eq. (5) represents the time constraint of onlinesales basic products from the traditional distribution channel to market.

$$
t b_{m 3 t} z z_{m 3 t}-t s_{m 3 t} \leq t m_{3 t}, \forall m \in M, t \in T
$$

Eq. (6) represents the lead time of cloth purchase, production time and the time constraint from traditional the distribution channel to market.

$$
\sum_{f \in F} t p_{f p t} x_{f p t}+\sum_{f \in F} t a_{f p t} y_{f p t}+c g \leq t w_{p t}, \quad \forall p \in P, \quad t \in T
$$

2) The conservation of production, transportation and storage

Eq. (7) represents the conservation between market and the seasonal made-to-order products which are sold through the online distribution channel.

$$
z Z_{m p t}=\alpha_{1 m} D_{1 p t}, \forall m \in M, \quad t \in T, p=1,2
$$

Eq. (8) represents the conservation between market and the basic products which are sold through the online distribution channel.

$$
z z_{m 3 t}=\alpha_{1 m}\left(D_{13 t}-\xi_{13 t}\right), \quad \forall m \in M, \quad t \in T
$$

Eqs. (9) and (10) respectively represent the conservation between the market and seasonal and between the market and basic products, both of which are sold through the traditional distribution channel.

$$
\begin{gathered}
z_{m p t}=\alpha_{2 m}\left(D_{2 p t}-\xi_{2 p t}\right), \quad \forall m \in M, \quad t \in T, \quad p=1,2 \\
z_{m 3 t}-z z_{m 3 t}=\alpha_{2 m}\left(D_{23 t}-\xi_{23 t}\right), \quad \forall m \in M, \quad t \in T
\end{gathered}
$$

Eq. (11) represents the demand conversation of seasonal products sold through the online distribution channel.

$$
\sum_{f \in F} s_{f m p t}=z z_{m p t}, \forall m \in M, t \in T, p=1,2
$$

Eq. (12) represents the situation where the basic products are not directly transported to consumers from the factory.

$$
s_{f m 3 t}=0, \forall f \in F, m \in M, t \in T
$$

Eq. (13) represents production conservation.

$$
y_{f p t}+\sum_{m \in M} s_{f m p t}=x_{f p t}, \quad \forall f \in F, p \in P, \quad t \in T
$$

Eqs. (14) and (15) represent inventory conservation.

$$
\begin{gathered}
w p_{p t}=\sum_{f \in F} y_{f p t}-\sum_{m \in M} z_{m p t}+w p_{p(t-1)}, \forall p \in P, t \in T \\
w p_{p 0}=0
\end{gathered}
$$

Eq. (16) represents transportation conservation.

$$
\sum_{f \in F} y_{f p t}=\sum_{w \in W}\left(D o_{w p t}+\xi_{w p(t-1)}-w p_{w p(t-1)}+g_{w p(t-1)}, \quad \forall p \in P, \quad t \in T\right.
$$

Eq. (17) represents demand conservation of seasonal products sold through the traditional distribution channel.

$$
\sum_{f \in F} y_{f p t}=\frac{1-\theta}{\theta} D_{1 p t}+\sum_{w \in W} g_{w p t}, \forall t \in T, p=1,2
$$


3) Constraint of production capacity:

$$
\sum_{p \in P} x_{f p t} \leq p a_{f t}, \quad \forall f \in F, t \in T
$$

4) The value range of each variable:

$$
\begin{gathered}
x_{f p t}, y_{f w p t}, z_{w m p t}, \quad z z_{m p t}, w p_{w p t}, s_{f m p t}, \xi_{w p t} \geq 0, \\
\forall f \in F, \quad p \in P, \quad t \in T, w \in W, \quad m \in M
\end{gathered}
$$

\subsection{Model solution}

The programming above is a mixed integer nonlinear programming model. The model involves many variables and complex constraints, making calculation of the model slow and difficult with traditional solving methods. Lingo 10.0 is a functional tool with high-speed, convenience and efficiency to build and resolve linear, nonlinear and integer optimization models.

\section{NUMERICAL SIMULATION}

\subsection{Simulation data}

Assumption that the production-distribution network consists of two factories, two salechannels and three markets, the maximum production capacity of two factories is 60,000 pieces. In the growth stage, the production efficiency levels of the two factories are respectively $1.2 \mathrm{~h}$ and $0.96 \mathrm{~h}$ per 1000 pieces. In the mature stage, the production efficiency levels of the two factories are respectively $0.4 \mathrm{~h}$ and $0.3 \mathrm{~h}$ per 1,000 pieces. In the decline stage, the production efficiency levels of the two factories are respectively $1.6 \mathrm{~h}$ and $1.2 \mathrm{~h}$ per 1,000 pieces. The market share of the online distribution channel is 0.32 while the market share of the traditional distribution channel is 0.68 . The price elasticity coefficient is 2 and the elasticity coefficient of cross price is 1 , and the time sensitivity coefficient is 1 . The purchase time is 700 hours. The delivery period promised by the factory to the traditional distribution channel is 960 hours. The delivery period of products 1 and 2 promised by the online distribution channel to consumers is 720 hours, and the delivery period of product 3 is 100 hours. Details of other parameters are in the Table I to Table X.

Table I: The basic demand of each product in various stages (thousand units).

\begin{tabular}{|c|c|c|c|}
\cline { 2 - 4 } \multicolumn{1}{c|}{} & $t=1$ & $t=2$ & $t=3$ \\
\hline$p=1$ & 20 & 38 & 10 \\
\hline$p=2$ & 15 & 24 & 6 \\
\hline$p=3$ & 9 & 10 & 8 \\
\hline
\end{tabular}

Table II: Unit stock cost of each product in different channels (yuan).

\begin{tabular}{|c|c|c|c|c|}
\cline { 3 - 5 } \multicolumn{2}{c|}{} & $t=1$ & $t=2$ & $t=3$ \\
\hline \multirow{3}{*}{$w=1$} & $p=1$ & 10 & 10 & 10 \\
\cline { 2 - 5 } & $p=2$ & 11 & 11 & 11 \\
\cline { 2 - 5 } & $p=3$ & 9 & 9 & 9 \\
\hline \multirow{3}{*}{$w=2$} & $p=1$ & 12 & 12 & 12 \\
\cline { 2 - 5 } & $p=2$ & 14 & 14 & 14 \\
\cline { 2 - 5 } & $p=3$ & 13 & 13 & 13 \\
\hline
\end{tabular}


Table III: Products demand of last season in different channels (thousand units).

\begin{tabular}{|c|c|c|c|c|}
\cline { 3 - 5 } \multicolumn{2}{c|}{} & $t=1$ & $t=2$ & $t=3$ \\
\hline \multirow{3}{*}{$w=1$} & $p=1$ & 4.2 & 9.8 & 1.45 \\
\cline { 2 - 5 } & $p=2$ & 5.2 & 7.8 & 1.45 \\
\cline { 2 - 5 } & $p=3$ & 2.3 & 2.7 & 2.5 \\
\hline \multirow{3}{*}{$w=2$} & $p=1$ & 9.8 & 23.5 & 5.95 \\
\cline { 2 - 5 } & $p=2$ & 10 & 19.8 & 5.95 \\
\cline { 2 - 5 } & $p=3$ & 5.8 & 6.8 & 5 \\
\hline
\end{tabular}

Table IV: The safety stock quantity in each channel and stage (thousand units).

\begin{tabular}{|c|c|c|c|c|}
\cline { 3 - 5 } \multicolumn{2}{c|}{} & $t=1$ & $t=2$ & $t=3$ \\
\hline \multirow{3}{*}{$w=1$} & $p=1$ & 0.6 & 0.8 & 0.5 \\
\cline { 2 - 5 } & $p=2$ & 0.6 & 0.8 & 0.5 \\
\cline { 2 - 5 } & $p=3$ & 0.2 & 0.2 & 0.2 \\
\hline \multirow{3}{*}{$w=2$} & $p=1$ & 0.8 & 1 & 0.6 \\
\cline { 2 - 5 } & $p=2$ & 0.8 & 1 & 0.6 \\
\cline { 2 - 5 } & $p=3$ & 0.3 & 0.3 & 0.2 \\
\hline
\end{tabular}

Table V: Unit retail price of each product in each channel and stage (yuan).

\begin{tabular}{|c|c|c|c|c|}
\cline { 3 - 5 } \multicolumn{2}{c|}{} & $t=1$ & $t=2$ & $t=3$ \\
\hline \multirow{3}{*}{$w=1$} & $p=1$ & 199 & 199 & 99 \\
\cline { 2 - 5 } & $p=2$ & 238 & 238 & 119 \\
\cline { 2 - 5 } & $p=3$ & 99 & 99 & 69 \\
\hline \multirow{3}{*}{$w=2$} & $p=1$ & 349 & 349 & 159 \\
\cline { 2 - 5 } & $p=2$ & 399 & 399 & 179 \\
\cline { 2 - 5 } & $p=3$ & 139 & 139 & 99 \\
\hline
\end{tabular}

Table VI: Unit production cost in various stages (yuan).

\begin{tabular}{|c|c|c|c|c|}
\cline { 2 - 5 } \multicolumn{2}{c|}{} & $t=1$ & $t=2$ & $t=3$ \\
\hline \multirow{3}{*}{$f=1$} & $p=1$ & 62 & 62 & 62 \\
\cline { 2 - 5 } & $p=2$ & 87 & 87 & 87 \\
\cline { 2 - 5 } & $p=3$ & 25 & 25 & 25 \\
\hline \multirow{3}{*}{$f=2$} & $p=1$ & 68 & 68 & 68 \\
\cline { 2 - 5 } & $p=2$ & 80 & 80 & 80 \\
\cline { 2 - 5 } & $p=3$ & 26 & 26 & 26 \\
\hline
\end{tabular}

Table VII: Unit shortage cost of each product in various stages (yuan).

\begin{tabular}{|c|c|c|c|c|}
\cline { 3 - 5 } \multicolumn{1}{c|}{} & $t=1$ & $t=2$ & $t=3$ \\
\hline \multirow{3}{*}{$w=1$} & $p=1$ & 8 & 8 & 8 \\
\cline { 2 - 5 } & $p=2$ & 9 & 9 & 9 \\
\cline { 2 - 5 }$w=2$ & $p=3$ & 11 & 11 & 11 \\
\hline \multirow{3}{*}{$w=1$} & 10 & 10 & 10 \\
\cline { 2 - 5 } & $p=2$ & 12 & 12 & 12 \\
\cline { 2 - 5 } & $p=3$ & 15 & 15 & 15 \\
\hline
\end{tabular}

Table VIII: Unit transportation efficiency (hour) and freight (yuan) from factory to distributor.

\begin{tabular}{|l|c|c|c|}
\cline { 2 - 4 } \multicolumn{1}{c|}{} & $p=1$ & $p=2$ & $p=3$ \\
\hline$f_{1}-w_{1}$ & $0.0032 / 9$ & $0.0032 / 9$ & $0.0032 / 9$ \\
\hline$f_{1}-w_{2}$ & $0.0108 / 12$ & $0.0108 / 12$ & $0.0108 / 12$ \\
\hline$f_{2}-w_{1}$ & $0.0084 / 10$ & $0.0084 / 10$ & $0.0084 / 10$ \\
\hline$f_{2}-w_{2}$ & $0.0096 / 11$ & $0.0096 / 11$ & $0.0096 / 11$ \\
\hline
\end{tabular}


Table IX: Unit transportation efficiency (hour) and freight (yuan) from distributor to market.

\begin{tabular}{|c|c|c|c|}
\cline { 2 - 4 } \multicolumn{1}{c|}{} & $p=1$ & $p=2$ & $p=3$ \\
\hline$w_{1}-m_{1}$ & $0.0372 / 9$ & $0.0372 / 9$ & $0.0372 / 9$ \\
\hline$w_{1}-m_{2}$ & $0.0508 / 12$ & $0.0508 / 12$ & $0.0508 / 12$ \\
\hline$w_{1}-m_{3}$ & $0.0484 / 10$ & $0.0484 / 10$ & $0.0484 / 10$ \\
\hline$w_{2}-m_{1}$ & $0.024 / 3$ & $0.024 / 3$ & $0.024 / 3$ \\
\hline$w_{2}-m_{2}$ & $0.018 / 4$ & $0.018 / 4$ & $0.018 / 4$ \\
\hline$w_{2}-m_{3}$ & $0.01 / 3$ & $0.01 / 3$ & $0.01 / 3$ \\
\hline
\end{tabular}

Table X: Unit transportation efficiency (hour) and freight (yuan) from factory to market.

\begin{tabular}{|c|c|c|c|}
\cline { 2 - 4 } \multicolumn{1}{c|}{} & $p=1$ & $p=2$ & $p=3$ \\
\hline$f_{1}-m_{1}$ & $0.013 / 15$ & $0.013 / 15$ & $0.013 / 15$ \\
\hline$f_{1}-m_{2}$ & $0.0125 / 13$ & $0.0125 / 13$ & $0.0125 / 13$ \\
\hline$f_{1}-m_{3}$ & $0.0113 / 12$ & $0.0113 / 12$ & $0.0113 / 12$ \\
\hline$f_{2}-m_{1}$ & $0.011 / 13$ & $0.011 / 13$ & $0.011 / 13$ \\
\hline$f_{2}-m_{2}$ & $0.0106 / 12$ & $0.0106 / 12$ & $0.0106 / 12$ \\
\hline$f_{2}-m_{3}$ & $0.01 / 10$ & $0.01 / 10$ & $0.01 / 10$ \\
\hline
\end{tabular}

According to the data above, in this paper, the LINGO10.0 is running under the environment in which the CPU is Pentium T3200 $(2.0 \mathrm{GHz})$ and the memory is $512 \mathrm{MB}$.

\subsection{Simulation results}

The optimal value of the target function is $Z=25209950$ yuan. Table XI reveals the full receipt and disbursement statement of an apparel enterprise under pre-sale mode. Figs. 2 to 4 reveal the optimal solutions of decision variables under pre-sale mode.

Table XI: The receipt and disbursement statement of apparel enterprise production-distribution network based on pre-sale mode (yuan).

\begin{tabular}{|c|c|c|c|c|c|}
\hline $\begin{array}{c}\text { Sales } \\
\text { revenue }\end{array}$ & $\begin{array}{c}\text { Shortage } \\
\text { cost }\end{array}$ & $\begin{array}{c}\text { Production } \\
\text { cost }\end{array}$ & $\begin{array}{c}\text { Storage } \\
\text { cost }\end{array}$ & Freight & $\begin{array}{c}\text { Punishment } \\
\text { cost }\end{array}$ \\
\hline 34593148 & 4764 & 8120200 & 51720 & 1192842 & 13672 \\
\hline
\end{tabular}

\subsection{Result analysis}

Figs. 2 to 4, reveal that in initial sales stage the pre-sold products through the online-sale channel are directly sold to consumers leaving no remaining inventory. After the pre-sale, due to variations in production and transportation efficiency, the factory fails to distribute the apparel products to consumers within the agreed timeframe, which results in delay to a certain extent. The delay will bring about negative feedback to online sales and even the risk of the goods being returned. But the feedback of the online sales channel can provide valuable guidance for ordering decision making to the traditional distribution channel. The inventory amount of the finished product in the initial sales stage is just 631 pieces, which reduces the stock and storage cost as well as production waste. Before the arrival of the peak season, the best-selling products will be for the second pre-sale through the online sales channel and demand information will be fed back to the factory and the traditional distribution channel after the pre-sale. For the apparel in peak season, the online sales channel faces aggravated delay. Though the total inventory in the traditional distribution channel has increased to 2197 pieces, the overall amount of overstocked inventory has sharply decreased by comparison. When the apparel enters the end season of sales, the online-sales channel connects with consumers through the direct model. The difference is that the traditional distribution channels manage inventory control very well in the previous two stages. At the end of sales 
season, the apparel enterprises may promote sales by offering discounts, resulting in profit reduction. At the end of sales season, the finished products inventory of the apparel supply chain under pre-sale mode is kept to only 1256 pieces.

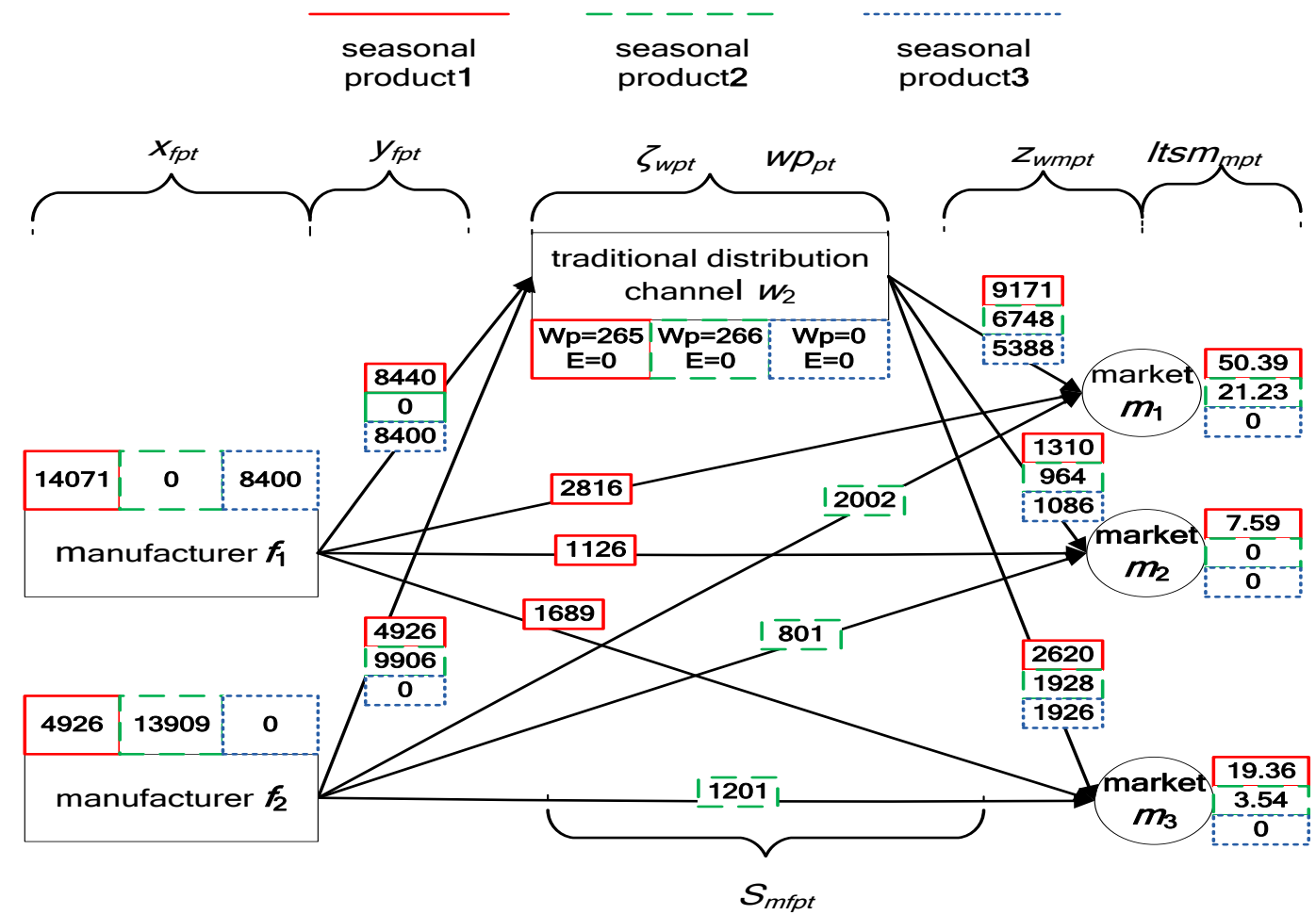

Figure 2: The optimal decision variables of apparel production-distribution network model based on pre-sale mode in initial sales stage.

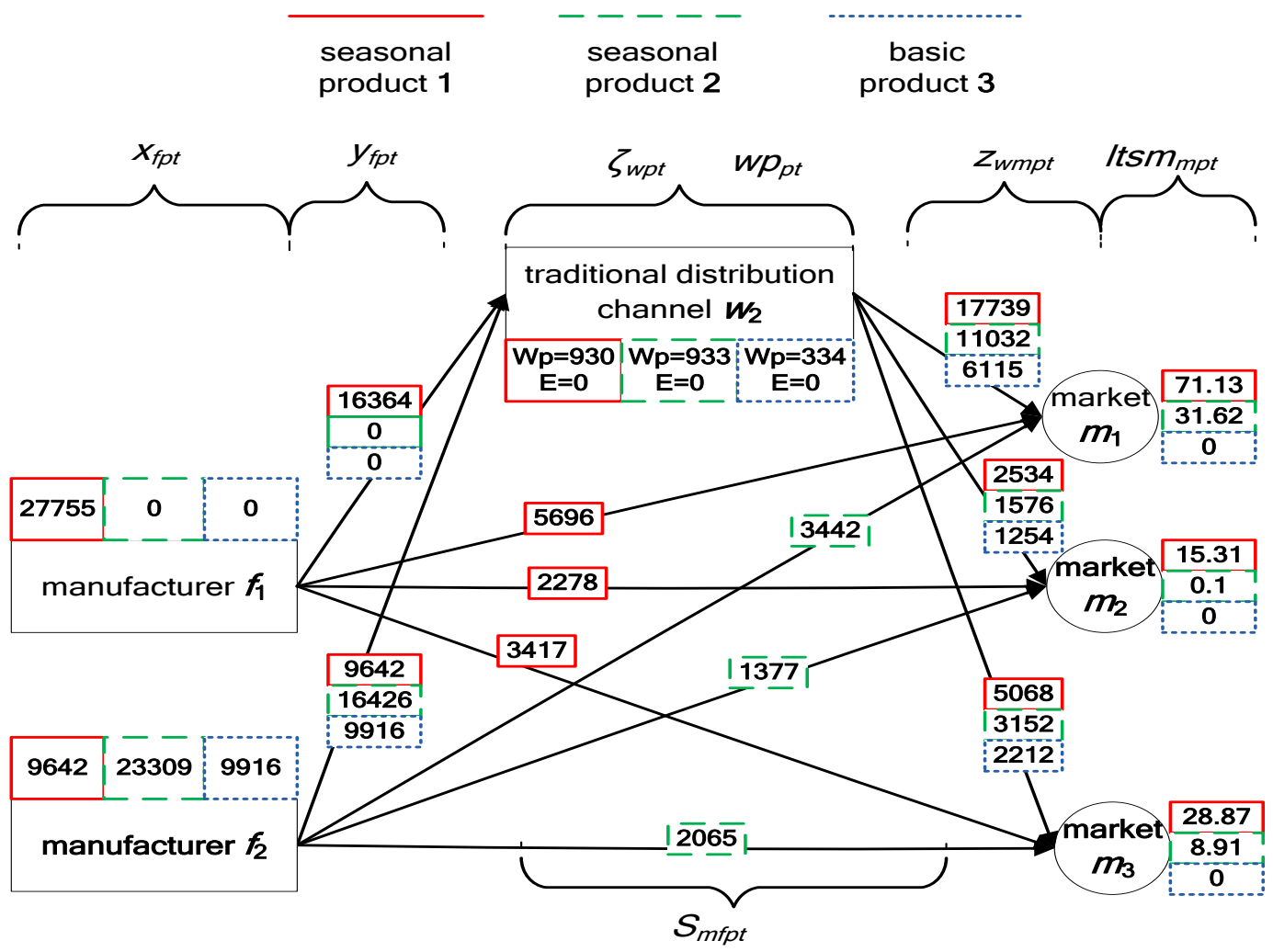

Figure 3: The optimal decision variables of apparel production-distribution network model based on pre-sale mode in the peak season of sales. 


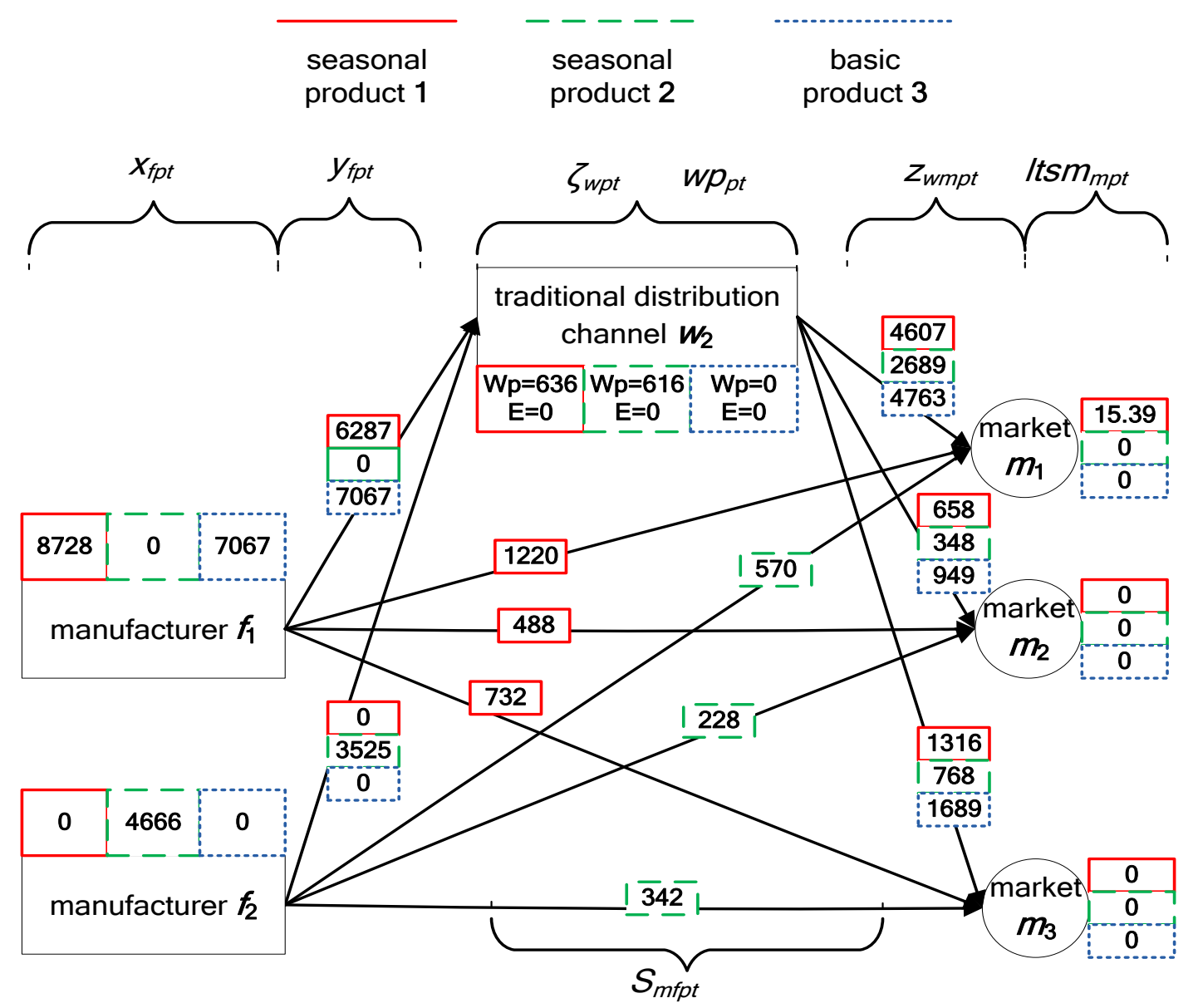

Figure 4: The optimal decision variables of apparel production-distribution network model based on pre-sale mode at the end of sales season.

\section{CONCLUSIONS}

By building a mixed-integer programming model, this paper extends the productiondistribution mode of the online-sales channel from the view of pre-sale. An optimization model is built of the production-distribution network of the apparel supply chain based on pre-sale mode by utilizing the order entry point as distinguished from the made-to-stock. To maximize the overall profit of the apparel supply chain, an extended production-distribution network model is built of a two-echelon supply chain comprised of both manufacturers and distributors, and the following conclusions are drawn through numerical simulation. In the pre-sale mode, the online-sales channel of the made-to-order apparel supply chain does not keep the stock of finished goods. While the market information feedback from pre-sales can provide valuable guidance for traditional distribution channels to help make accurate market predictions, which allows the traditional distribution channel to keep any shortage under control. This increases sales revenue and overall profit and solves the problem of overstocked inventory.

\section{ACKNOWLEDGEMENTS}

This work was supported by Zhejiang Natural Science Foundation under Award Number LY15G030021, the National Social Science Foundation of China under Award Number 12CGL045 and the Postdoctoral Science Foundation of China under Award Number 2013M531541. 


\section{REFERENCES}

[1] Lowson, B.; King, R.; Hunter, A. (2006). The way of quick response: the supply chain to meet customer demand, Mechanical Industry Press, Beijing

[2] Bergvall-Forsberg, J.; Towers, N. (2007). Creating agile supply networks in the fashion industry: A pilot study of the European textile and clothing industry, Journal of the Textile Institute, Vol. 98, No. 4, 377-386, doi:10.1080/00405000701502925

[3] Fisher, M.; Rajaram, K.; Raman, A. (2001). Optimizing inventory replenishment of retail fashion products, Manufacturing \& Service Operations Management, Vol. 3, No. 3, 230-241, doi: $10.1287 / \mathrm{msom} \cdot 3.3 .230 .9889$

[4] Chiang, W.-Y. K.; Monahan, G. E. (2005). Managing inventories in a two-echelon dual-channel supply chain, European Journal of Operational Research, Vol. 162, No. 2, 325-341, doi:10.1016/j.ejor.2003.08.062

[5] Gao, X.-M. (2005). Supply chain control research of achieve the optimal inventory clothing garment industry, Donghua University, Shanghai

[6] Brun, A.; Castelli, C. (2008). Supply chain strategy in the fashion industry: Developing a portfolio model depending on product, retail channel and brand, International Journal of Production Economics, Vol. 116, No. 2, 169-181, doi:10.1016/j.ijpe.2008.09.011

[7] Li, Y.-J.; Wei, C.-S.; Cai, X.-Q. (2012). Optimal pricing and order policies with B2B product returns for fashion products, International Journal of Production Economics, Vol. 135, No. 2, 637-646, doi:10.1016/j.ijpe.2011.05.004

[8] Zhou, J.-H.; Xu, Q. (2008). Analysis of system dynamics model in garment supply chain, Journal of Textile Research, Vol. 29, No. 12, 122-125

[9] Xu, Z. (2010). RFID-based intelligent management of warehousing distribution of apparel supply chain, Journal of Textile Research, Vol. 31, No. 9, 137-142

[10] Weng, Z. K.; Parlar, M. (1999). Integrating early sales with production decisions: analysis and insights, IIE Transactions, Vol. 31, No. 11, 1051-1060, doi:10.1023/A:1007671407701

[11] Tang, C. S.; K. Rajaram, A.; Alptekinoglu, A.; Ou, J.-H. (2004). The benefits of advance booking discount programs: model and analysis, Management Science, Vol. 50, No. 4, 465-478, doi: $10.1287 / \mathrm{mnsc} .1030 .0188$

[12] Moe, W. W.; Fader, P. S. (2002). Using advance purchase orders to forecast new product sale, Marketing Science, Vol. 21, No. 3, 347-364, doi:10.1287/mksc.21.3.347.138

[13] Li, Y.-J.; Xu, L.; Yang, X.-L. (2012). Advance selling, return policy and failure false return for a newsvendor retailer, Nankai Business Review, Vol. 15, No. 5, 105-113

[14] Boyaci, T.; Ozer, O. (2010). Information acquisition for capacity planning via pricing and advance selling: When to stop and act?, Operations Research, Vol. 58, No. 5, 1328-1349, doi:10.1287/opre.1100.0798

[15] Zhang, L.; Yan, Z.-Q.; Ma, Z. (2012). Dynamic optimization model of supply chain network based on stage demand characteristics, Computer Integrated Manufacturing Systems, Vol. 18, No. 6, 1263-1270

[16] Sun, Y.-L.; Zhou, J. (2007). Output model for high-tech products during the renewing process, Journal of Systems Engineering, Vol. 22, No. 3, 262-267

[17] Zhang, L.; Ma, L.; Yuan, C.-A. (2013). Comparative study on production-distribution strategy of perishable electron product, Soft Science, Vol. 27, No. 2, 36-40

[18] Xu, X.-H.; Yu, S.-Q. (2007). Comparison of three inventory models of short life cycle products, Journal of Management Sciences in China, Vol. 10, No. 4, 9-15 